\title{
Electrochemical tuning of the activity and structure of a copper- cobalt micro-nano film on a gold electrode, and its application to the determination of glucose and of Chemical Oxygen Demand
}

\author{
Jinqi Wang $\cdot \mathrm{Na}$ Yao $\cdot$ Mei Li $\cdot$ Jia Hu $\cdot$ Jianwei Chen • \\ Qiaoling Hao $\cdot$ Kangbing Wu $\cdot$ Yikai Zhou
}

Received: 19 May 2014 / Accepted: 30 August 2014 / Published online: 17 September 2014

(C) The Author(s) 2014. This article is published with open access at Springerlink.com

\begin{abstract}
Micro-nano structured Cu-Co was in situ fabricated on the surface of a gold electrode via electrochemical reduction of $\mathrm{CuCl}_{2}$ and $\mathrm{Co}\left(\mathrm{NO}_{3}\right)_{2}$. It is shown that the shape of the particles can be controlled by variation of deposition current, deposition time, $\mathrm{pH}$ value and the ratio of $\mathrm{Cu}$ (II) and $\mathrm{Co}$ (II) ions. If prepared under current of $-200 \mu \mathrm{A}$ in $0.1 \mathrm{M}, \mathrm{pH} 4.0$ acetate buffer solution, the film possesses high catalytic activity towards the electrochemical oxidation of glucose at a largely increased oxidation current compared to a nonmodified surface. The electrochemical activity of this sensor can be easily tuned. Glucose is a standard compound for evaluating the chemical oxygen demand (COD), and we have therefore studied the application of the sensor to the determination of this parameter. Under optimized conditions, the sensor has linear response to glucose in the $1.92-768 \mathrm{mg} \mathrm{L}^{-1}$ concentration range, and the detection limit is $0.609 \mathrm{mg} \mathrm{L}^{-1}$ (at an $\mathrm{S} / \mathrm{N}$ ratio of 3). A large number of surface water samples was studied, and the results obtained by this method were found to be linearly correlated to those obtained by the dichromate method $(\mathrm{r}=0.995 ; n=33)$.
\end{abstract}

Keywords Chemical oxygen demand (COD) .

Electrochemical sensor · Micro-nano $\mathrm{Cu}-\mathrm{Co}$.

Gold electrode $\cdot$ Electro deposition

Electronic supplementary material The online version of this article (doi:10.1007/s00604-014-1353-z) contains supplementary material, which is available to authorized users.

$\mathrm{J}$. Wang $\cdot \mathrm{N}$. Yao $\cdot \mathrm{M}$. Li $\cdot$ J. Hu $\cdot$ J. Chen $\cdot$ Q. Hao $\cdot$ K. Wu $\cdot$ Y. Zhou $(\bowtie)$

MOE Key Lab of Environment and Health, School of Public Health, Tongji Medical College, Huazhong University of Science and Technology, Wuhan 430030, China

e-mail: zhouyikaitjmu@163.com

K. Wu

School of Chemistry and Chemical Engineering, Huazhong

University of Science and Technology, Wuhan 430074, China

\section{Introduction}

Chemical oxygen demand (COD) is defined as the number of oxygen equivalents consumed in the oxidation of organic compounds using strong oxidizing agents $[1,2]$. However, the application of the standard determination method has often been limited by many intrinsic drawbacks, including time consuming process, complicated operation, consumption of expensive $\left(\mathrm{Ag}_{2} \mathrm{SO}_{4}\right)$, highly corrosive $\left(\mathrm{H}_{2} \mathrm{SO}_{4}\right)$ and toxic $\left(\mathrm{Cr}_{2} \mathrm{O}_{7}{ }^{2-}\right.$ and $\left.\mathrm{HgSO}_{4}\right)$ reagents [3, 4]. Thus, numerous efforts have been made to develop simple and rapid analytical method for COD [5, 6]. Among them, the electrochemical method has considered as a promising method for COD detection due to its high sensitivity, short analysis time, low cost and handling convenience. In order to achieve high response signal, development of highly sensitive electrode material is crucial. So far, different materials were successfully used to construct sensing electrodes for COD. The electrocatalytic oxidation method utilized $\mathrm{TiO}_{2}$ nanorod [7], $\mathrm{TiO}_{2}$ film [8], $\mathrm{Rh}_{2} \mathrm{O}_{3} / \mathrm{Ti}$ [9], Ti/ $\mathrm{Sb}-\mathrm{SnO}_{2} / \mathrm{PbO}_{2}$ [10], $\mathrm{AgO}-\mathrm{CuO}$ [11] and photocatalytic nano- $\mathrm{ZnO} / \mathrm{TiO}_{2}[2]$ as sensors to oxidize organic compounds. However, the fabrication procedure was complicated and time-consuming compared with electrodeposition method. Boron-doped diamond (BDD) [12-14], nano-Pt [15] and Nano- $\mathrm{PbO}_{2}$ [16] have been reported with satisfied performance for COD determination. However, their application in practice was limited by the complicated fabrication process requiring special instrument leading to high cost of BDD and Pt. Nano- $\mathrm{Cu}[3,17]$ and $\mathrm{F}-\mathrm{PbO}_{2}[15]$ were also fabricated for COD determination. Nevertheless, the methods were incapable of widespread application due to their high detection limit.

Chemical oxygen demand (COD), a major indicator of organic pollution in waters, is widely recognized as one of the most important parameters for water quality [18-20]. Up to now, many countries, such as China and Japan, have accepted it as a national standard for organic pollution 
evaluation [21]. Although the overall reduction of COD is complicated, it was found that some simple reactivities are common and can be enhanced to improve the catalytic activity of sensing films. The typical reaction of COD reduction is presented as:

$$
\begin{aligned}
\mathrm{C}_{y} \mathrm{H}_{m} \mathrm{O}_{j} N_{k} & +\left(y+\frac{m}{4}-\frac{j}{2}-\frac{3}{4} k\right) \mathrm{O}_{2} \rightarrow y \mathrm{CO}_{2} \\
& +\left(\frac{m}{2}-\frac{3}{2} k\right) \mathrm{H}_{2} \mathrm{O}+\mathrm{kNH}_{3}
\end{aligned}
$$

From this equation we could see that the reduction of COD includes one common progress: oxygen-oxygen bandbreaking.

Mixing two or more metals to generate intermetallic compounds can result in a catalyst that has distinct properties from its monometallic components. The rich diversity of the compositions, structure and properties of intermetallic compounds has led to their widespread application in field of catalysis [22]. During the searching for abundant, inexpensive, and efficient electrocatalytic materials, researchers found that the addition of metals, which bind oxygen strongly, can lower oxygen binding to other metals and easily break the oxygenoxygen bond and eventually improve their catalytic activity [23]. As known, $\mathrm{Cu}$ and $\mathrm{Co}$ are both metals that can bind oxygen strongly and tend to reduce the oxygen easily [24]. Then we could speculate that the alloy composition in $\mathrm{Cu}-\mathrm{Co}$ sensing film may not only prevents Co from being corroded too rapidly [25], but also exhibits the synergistic effects on oxygen-oxygen band breaking, and ultimately enhance the response signal of COD detection.

In this work, micro-nano $\mathrm{Cu}$-Co composite was in situ fabricated on the surface of gold electrode via electrochemical deposition using $\mathrm{Co}\left(\mathrm{NO}_{3}\right)_{2}$ and $\mathrm{CuCl}_{2}$ as the precursor. The $\mathrm{Cu}-\mathrm{Co}$ composite was characterized by scanning electron microscopy (SEM), which revealed that this composite formed a film with a rough structure and a large surface area on gold electrode. Linear sweep voltammetry (LSV) was employed to illustrate the electrochemical oxidation of glucose in alkaline solution. The influence of electrodeposition parameters on glucose response signal was studied, and then a novel electrochemical sensor was developed. Compared with the reported sensors as shown in table 1, this new one exhibited higher sensitivity, higher $\mathrm{Cl}^{-1}$ tolerance and the detection limit was as low as $0.609 \mathrm{mg} \mathrm{L}^{-1} \mathrm{COD}$. Moreover, this new sensor was successfully applied to the determination of COD in surface water, which indicates that this micro-nano composite could be used as an electrocatalyst for the sensing and detection of COD in real water samples. The present work not only provided a sensitive electrochemical method for the determination of COD in surface water, but also demonstrated the promising applications of intermetallic micro-nano material composite as highly active sensing materials in high-performance electrochemical sensors.

\section{Experimental}

\section{Reagents}

All chemicals were of analytical grade and used as received. $\mathrm{Co}\left(\mathrm{NO}_{3}\right)_{2}, \mathrm{CuCl}_{2}, \mathrm{NaOH}, \mathrm{K}_{2} \mathrm{Cr}_{2} \mathrm{O}_{7}, \mathrm{Ag}_{2} \mathrm{SO}_{4}, \mathrm{HgSO}_{4}$, $\left(\mathrm{NH}_{4}\right)_{2} \mathrm{Fe}\left(\mathrm{SO}_{4}\right)_{2}, \mathrm{HCl}, \mathrm{NaNO}_{3}$, acetic acid and sodium acetate were purchased from the Sinopharm Group Chemical Reagent Co. Ltd. (China, http://en.reagent.com.cn/). Doubly distilled water was used throughout. Surface water samples were collected on-site from different lakes and rivers in Wuhan (China). Water samples were stored in dark at $4{ }^{\circ} \mathrm{C}$ and analyzed within $48 \mathrm{~h}$.

\section{Instruments}

Electrochemical measurements were performed on a CHI660D Electrochemical Workstation (Chenhua Instrument, Shanghai, China http://www.chinstr.com/) with a conventional three-electrode system. The working electrode is a micro-nano $\mathrm{Cu}$-Co modified gold electrode, the reference electrode is a saturated calomel electrode (SCE), and the counter electrode is a platinum wire. Scanning electron microscopy (SEM) was performed with a Quanta 200 microscope (FEI Company, Netherlands, http://www.fei.com/).

\section{Preparation of micro-nano $\mathrm{Cu}-\mathrm{Co}$ sensing film}

Before electrodeposition, the gold electrode with diameter of $3 \mathrm{~mm}$ was polished with $0.05 \mu \mathrm{m}$ alumina slurry, and then sonicated in doubly distilled water to give a clean surface. After that, micro-nano $\mathrm{Cu}-\mathrm{Co}$ sensing film was formed on $3 \mathrm{~mm}$ gold electrode surface under $-200 \mu \mathrm{A}$ for $100 \mathrm{~s}$ in $0.1 \mathrm{M}$, in $\mathrm{pH} 4.0$ acetate buffer solution containing $27 \mathrm{mM}$ $\mathrm{CuCl}_{2}, 3 \mathrm{mM} \mathrm{Co}\left(\mathrm{NO}_{3}\right)_{2}$ (vs. SCE). Finally, the resulting electrode was rinsed with re-distilled water to remove any adsorbed species. For comparison, gold electrode was also prepared following a similar procedure in the absence of $\mathrm{Cu}^{2+}$ and $\mathrm{Co}^{2+}$.

Detection of COD using standard dichromate method

The dichromate method was used to measure COD value according to the National Standard of China (GB 11914 89). Water sample solution $(10.0 \mathrm{~mL})$ and $0.025 \mathrm{M} \mathrm{K}_{2} \mathrm{Cr}_{2} \mathrm{O}_{7}$ solution $(5.0 \mathrm{~mL})$ were added into a cuvette, and then refluxed for $2 \mathrm{~h}$ in a thermostat at $160{ }^{\circ} \mathrm{C}$.

After that, the excess of dichromate was determined by titration using $0.005 \mathrm{M}\left(\mathrm{NH}_{4}\right)_{2} \mathrm{Fe}\left(\mathrm{SO}_{4}\right)_{2}$ as the titrant. Finally, 
Table 1 Comparison of electrochemical sensors for COD

\begin{tabular}{|c|c|c|c|c|c|c|}
\hline Sensing material & $\begin{array}{l}\text { Detection limit } \\
\left(\mathrm{mg} \mathrm{L}^{-1}\right)\end{array}$ & $\begin{array}{l}\text { Linearity range } \\
\left(\mathrm{mg} \mathrm{L}^{-1}\right)\end{array}$ & $\begin{array}{l}\text { Sensitivity } \\
\left(\mu \mathrm{A} /\left(\mathrm{mg} \mathrm{L}^{-1} \mathrm{COD}\right)\right)\end{array}$ & $\begin{array}{l}\text { Tolerance of } \mathrm{Cl}^{-1} \\
\text { (M) }\end{array}$ & $\begin{array}{l}\text { Detection Potential } \\
\text { (V) }\end{array}$ & Reference \\
\hline $\mathrm{TiO} 2$ nano-rod array & 18.3 & $20-280$ & - & - & 0.5 & [7] \\
\hline Cobalt oxide & 1.1 & $1.7-170$ & 1.00 & 0.02 & 0.8 & {$[26]$} \\
\hline $\mathrm{F}-\mathrm{PbO} 2$ & 15 & $100-1200$ & 0.000230 & - & 1.3 & {$[15]$} \\
\hline $\mathrm{Cu} / \mathrm{CuO}$ & 20.3 & $53-2801$ & 0.472 & - & - & {$[17]$} \\
\hline $\mathrm{Rh} 2 \mathrm{O} 3 / \mathrm{Ti}$ & 20.0 & $50-2000$ & 0.0220 & 0.017 & 1.3 & [9] \\
\hline $\mathrm{BDD}^{\mathrm{a}}$ & 1 & $2-175$ & 0.0909 & - & 2.8 & {$[27]$} \\
\hline $\mathrm{TiO} 2 / \mathrm{Ti} / \mathrm{TiO} 2-\mathrm{Pt}$ & 9.5 & $25-380$ & 3.55 & 0.040 & - & [28] \\
\hline $\mathrm{Cu}$ & 3.6 & $4.8-600$ & 0.454 & 0.02 & 0.8 & {$[3]$} \\
\hline $\mathrm{Pt}$ & 1.83 & - & 0.0260 & - & 0.45 & [29] \\
\hline $\mathrm{Cu} 2 \mathrm{O}-\mathrm{TNTAs}^{\mathrm{b}}$ & 15 & $20-300$ & 1.45 & 0.0056 & 0.3 & [30] \\
\hline $\mathrm{Cu}-\mathrm{Co}$ & 0.609 & $1.92-768$ & 0.888 & 0.02 & 0.6 & This work \\
\hline
\end{tabular}

${ }^{a}$ BDD: boron-doped diamond

b TNTAs: TiO2 nanotube arrays electrode

the value of COD was calculated after subtracting the blank value of doubly distilled water.

Linear Sweep Voltammetry and amperometric detection of COD using micro-nano $\mathrm{Cu}-\mathrm{Co}$ modified gold electrode

The linear sweep voltammetry (LSV) detection was employed to obtain the best reaction conditions. By detecting the oxidation current of glucose under various reaction conditions, the optimal operating conditions were determined.

The amperometric detection under well-stirred condition was used to measure the value of COD. The detected potential was at $0.6 \mathrm{~V}$ and the electrolyte was $0.1 \mathrm{M} \mathrm{NaOH}$ solution. The observed current on $\mathrm{Cu}-\mathrm{Co}$ surface was allowed to reach a steady state, and then the standard sample or the real surface water sample was added. The net current increase was measured as the response current of COD. All experiments were carried out at ambient temperature.

\section{Results}

Current tuning morphology and electro catalytic activity of Cu-Co film

The influence of metal ion concentration, deposition medium and deposition time on the activity of $\mathrm{Cu}-\mathrm{Co}$ was explored (see Supplementary Material). It's found that $\mathrm{Cu}$-Co sensing film prepared in $0.1 \mathrm{M}, \mathrm{pH} 4.0$ acetate buffer with reduction time of $100 \mathrm{~s}$ using $27 \mathrm{mM} \mathrm{Cu}^{2+}$ and $3 \mathrm{mM} \mathrm{Co}^{2+}$ as precursor exhibits the highest electrochemical activity, and was employed throughout.
Electrochemical deposition has been widely used in preparing coatings with different functions because of its simple operation and low cost [31-33]. As the deposited current influences the morphology of prepared particles greatly, different deposited currents were applied and the morphology of prepared particles was characterized using $0.1 \mathrm{M}, \mathrm{pH} 4.0$ acetate buffer with reduction time of $100 \mathrm{~s}$. As shown in Fig. 1, when the deposited current was -100 and $-150 \mu \mathrm{A}$ (Fig. 1B, C), the electrodeposited $\mathrm{Cu}-\mathrm{Co}$ films are consisting of few irregular flowerlike micro particles, besides, the size and density of them grows as time lasts. However, nothing appeared on the bare gold surface if reducing without $\mathrm{Cu}^{2+}$ and $\mathrm{Co}^{2+}$ (Fig. 1A). As the reduction current of $-200 \mu \mathrm{A}$, micro and submicro needle-like, rod-like, flake-like and grain particles started to form on gold surface, among which numerous nanoparticles assembled on substrates with diameters ranging from $40 \mathrm{~nm}$ to $80 \mathrm{~nm}$ (Fig. 2D). This may be caused by the fact that deposition current of $-200 \mu \mathrm{A}$ enabled diversified types of crystal to nucleate and enabled crystal nucleation and growth to take place all over gold surface. For deposited current of $-250 \mu \mathrm{A}$ (Fig. 2E), the density of fully developed particles increases as well as their sizes (diameter and height) and nanoparticles start to conglomerate while few irregular particles, $>1 \mu \mathrm{m}$ in diameter, distribute among them. The size and density of particles in the $\mathrm{Cu}-\mathrm{Co}$ film increases even further when reduction current moved down to $-300 \mu \mathrm{A}$ (Fig. 2F), with giant flake-like particles appearing on the asdeposit film and nanoparticles hardly to find. Otherwise, sensing film deposited at $-200 \mu \mathrm{A}$ under the condition of $0.1 \mathrm{M}, \mathrm{pH} 4.0$ acetate buffer, with $30 \mathrm{mM} \mathrm{CuCl}_{2}$ as the precursor, was also depicted. As shown in Fig. S5, a relatively thick coating consisted of numerous micro flake-like particles, accompanying with lots of submicro grain particles assembling on substrates. Apparently, the shape of $\mathrm{Cu}-\mathrm{Co}$ film can 
Fig. 1 SEM images of bare gold surface $(\mathrm{A})$ and the prepared $\mathrm{Cu}-$ Co at $-100 \mu \mathrm{A}(\mathrm{B}),-150 \mu \mathrm{A}(\mathrm{C})$, $-200 \mu \mathrm{A}(\mathrm{D}),-250 \mu \mathrm{A}(\mathrm{E})$, $-300 \mu \mathrm{A}(\mathrm{F})$ and micro-nano $\mathrm{Cu}$ at $-200 \mu \mathrm{A}(\mathrm{G})$

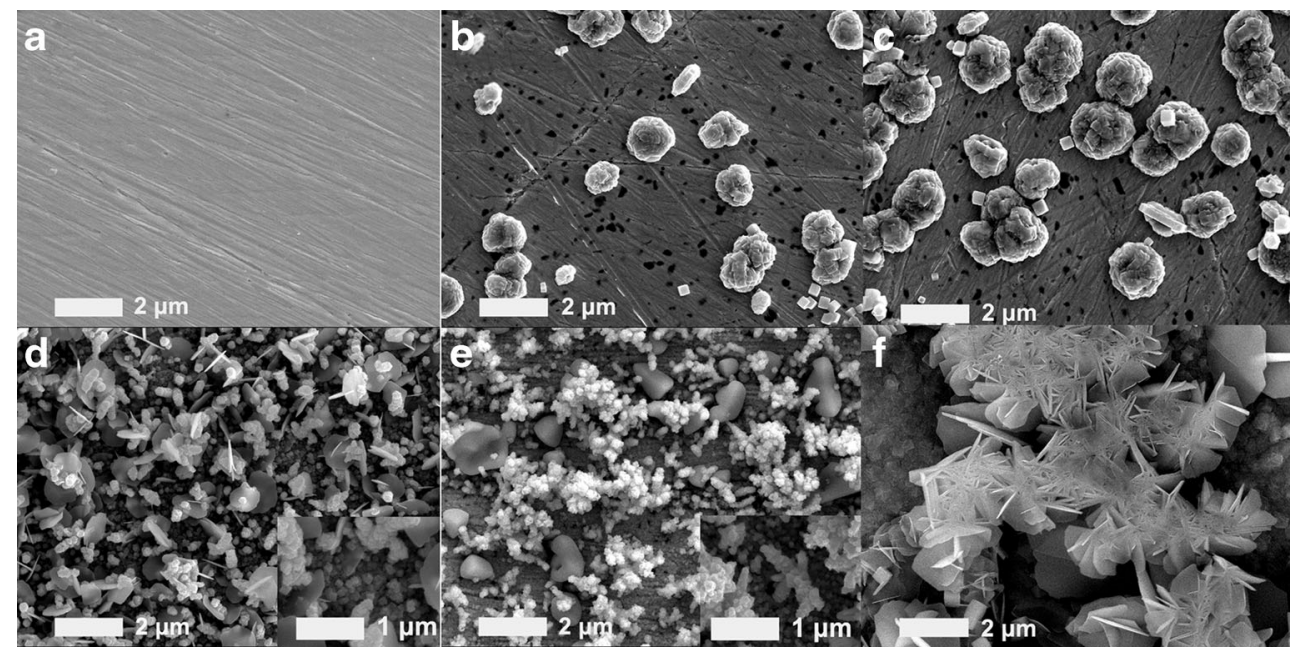

be easily tuned by variation of the reduction current, at the current value of $-200 \mu \mathrm{A}$, the gold surface was covered by sensing film that exhibiting high surface roughness and possessing numerous micro-nano particles, and therefore provided large response area and numerous active sites.

In order to elucidate the relationship between the electrochemical activity of micro-nano $\mathrm{Cu}-\mathrm{Co}$ and its shape, the electrochemical oxidation of glucose taking place on the surface of micro-nano $\mathrm{Cu}$-Co that prepared at different currents was studied using linear sweep voltammetry (LSV). Fig. 2A displays the LSV curves of $19.2 \mathrm{mg} \mathrm{L}^{-1}$ glucose in $0.1 \mathrm{M}$ $\mathrm{NaOH}$ on the surface of different $\mathrm{Cu}-\mathrm{Co}$ film, and Fig. 2B shows the variation of response signal with the deposition current. On the bare gold electrode, the oxidation peak current of glucose was hardly seen (curve a and the inset), suggesting that bare gold surface possessed much lower electrochemical activity to the oxidation of glucose. However, glucose was easily oxidized at the surface of micro-nano $\mathrm{Cu}-\mathrm{Co}$, and obvious oxidation peak appeared, indicating that micro-nano

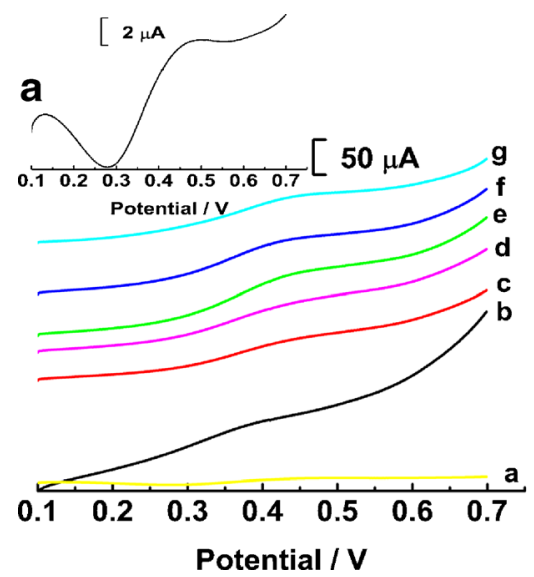

Fig. 2 A: The LSV curves of $19.2 \mathrm{mg} \mathrm{L}^{-1}$ glucose on bare gold surface (a), micro-nano $\mathrm{Cu}$ at $-200 \mu \mathrm{A}$ (d) and the resulting micro-nano $\mathrm{Cu}-\mathrm{Co}$ at $-100 \mu \mathrm{A}(\mathrm{b}),-150 \mu \mathrm{A}(\mathrm{c}),-200 \mu \mathrm{A}(\mathrm{e}),-250 \mu \mathrm{A}(\mathrm{f})$, and $-300 \mu \mathrm{A}(\mathrm{g})$. Insert plot: LSV curves of $19.2 \mathrm{mg} \mathrm{L}^{-1}$ glucose on bare gold surface. $\mathrm{B}$ :
$\mathrm{Cu}-\mathrm{Co}$ exhibits high activity to the oxidation of glucose. When the deposition current shifts from -100 to $-200 \mu \mathrm{A}$ (curve b-c, e), the response current of glucose increases remarkably. With further increasing the deposition current to -250 (curve f) and $-300 \mu \mathrm{A}$ (curve e), the response current of glucose decreases obviously. Clearly, the micro-nano $\mathrm{Cu}-\mathrm{Co}$ that prepared at $-200 \mu \mathrm{A}$ exhibits highest response activity to the electrochemical oxidation of glucose. Besides, the LSV curves of glucose on the surface of electrodeposited copper film was also depicted (curve d) which is inferior than that on micro-nano $\mathrm{Cu}-\mathrm{Co}$ film fabricated under the same condition (curve e). From the SEM images, it is observed that the particle size of micro-nano $\mathrm{Cu}-\mathrm{Co}$ that prepared at $-200 \mu \mathrm{A}$ is smaller, and the arrangement was regular on the gold surface. There's no doubt that the oxidation signal of glucose on the surface of micro-nano $\mathrm{Cu}-\mathrm{Co}$ was much higher. This phenomenon reveals that micro-nano $\mathrm{Cu}$-Co has unique properties which could enhance the oxidation signal of glucose largely.

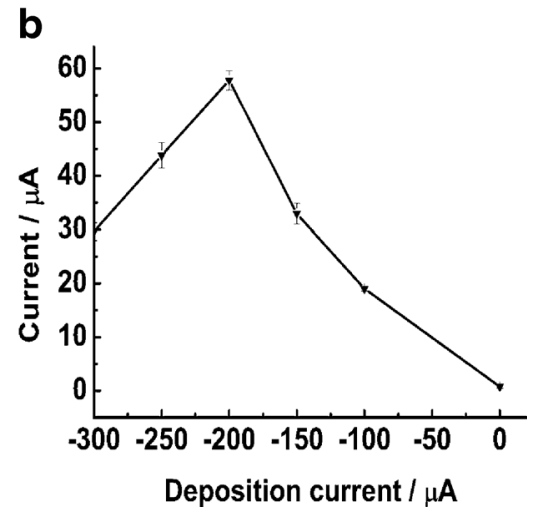

Variation of the oxidation peak current of $19.2 \mathrm{mg} \mathrm{L}^{-1}$ glucose on micronano $\mathrm{Cu}-\mathrm{Co}$ as the reduction deposition current. The error bars represent the standard deviation of repetitive measurements $(n=3)$ 
Fig. 3 A: The amperometric response of micro-nano $\mathrm{Cu}-\mathrm{Co} /$ gold electrode to glucose of different COD values in $0.1 \mathrm{M}$ $\mathrm{NaOH}$ at $0.6 \mathrm{~V}$. B: Calibration curve for COD values of glucose on micro-nano $\mathrm{Cu}-\mathrm{Co}$. Other conditions are as in Fig. 2
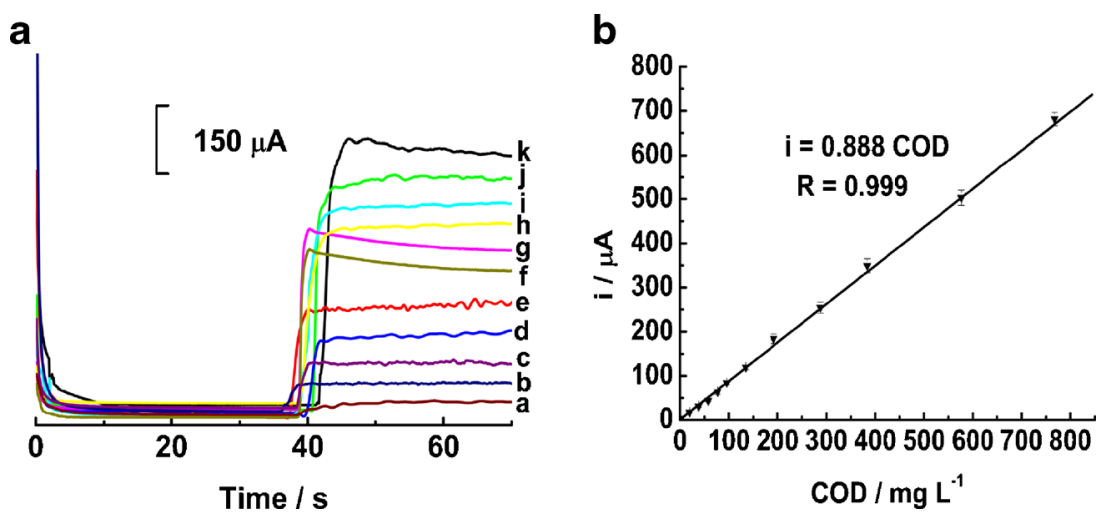

\section{Detection of COD}

It is very convenient to select some substances as the standard reagent for electrochemical detection of COD. Herein, glucose was used as the standard compound, and its oxidation current on micro-nano $\mathrm{Cu}-\mathrm{Co} /$ gold surface was applied to evaluate the value of COD. The COD value of glucose standard solution was detected using conventional dichromate method. For glucose solution, the value of COD was measured to be $380.6 \mathrm{mg} \mathrm{L}^{-1}$ of $\mathrm{O}_{2}$ using the conventional dichromate method, which consists with the theoretic value of $384 \mathrm{mg} \mathrm{L}^{-1}$ of $\mathrm{O}_{2}$ [34].

In order to choose a suitable medium for the electrochemical detection of COD, the oxidation peak response of glucose in $\mathrm{NaOH}$ solution with different concentrations were studied using linear sweep voltammetry. Micro-nano $\mathrm{Cu}-\mathrm{Co}$ was prepared at $-200 \mu \mathrm{A}$ for $100 \mathrm{~s}$ in $0.1 \mathrm{M}$, pH 4.0 acetate buffer containing $27 \mathrm{mM} \mathrm{CuCl}_{2}$ and $3 \mathrm{mM}$ $\mathrm{Co}\left(\mathrm{NO}_{3}\right)_{2}$. Fig. S6 illustrates the effect of concentration of $\mathrm{NaOH}$ on the oxidation current of glucose solution with COD of $19.2 \mathrm{mg} \mathrm{L}^{-1}$. It is found that the oxidation current of glucose notably enhanced with $\mathrm{NaOH}$ concentration over the range from 0.05 to $0.1 \mathrm{M}$. When the concentration of $\mathrm{NaOH}$ is higher than $0.1 \mathrm{M}$, the oxidation signal of glucose begins to decrease. Thus $0.1 \mathrm{M} \mathrm{NaOH}$ was employed to obtain high electrochemical activity.
Amperometric detection of COD

Amperometric detection, a simple and powerful analytical method, was used to detect the value of COD. Fig. 3A depicts the typical amperometric response of different-valued COD glucose solution on micro-nano $\mathrm{Cu}-\mathrm{Co}$ surface in $0.1 \mathrm{M}$ $\mathrm{NaOH}$ solution. When the oxidation potential is controlled at $0.6 \mathrm{~V}$, the background current of micro-nano $\mathrm{Cu}-\mathrm{Co}$ decreases dramatically during the first $5 \mathrm{~s}$, and then attains a steady state at about $15 \mathrm{~s}$. After addition of glucose solution with COD value of $19.2 \mathrm{mg} \mathrm{L}^{-1}$ at about $40 \mathrm{~s}$, a slight response is observed (curve a). When adding glucose solution with COD value of $38.4 \mathrm{mg} \mathrm{L}^{-1}$, an obvious oxidation current step is observed (curve b). If we gradually increase the COD value to $57.6 \mathrm{mg} \mathrm{L}^{-1}$ (curve c), $76.8 \mathrm{mg} \mathrm{L}^{-1}$ (curve d), $96 \mathrm{mg} \mathrm{L}^{-1}$ (curve e), $134.4 \mathrm{mg} \mathrm{L}^{-1}$ (curve f), $192 \mathrm{mg} \mathrm{L}^{-1}$ (curve g), $288 \mathrm{mg} \mathrm{L}^{-1}$ (curve h), $384 \mathrm{mg} \mathrm{L}^{-1}$ (curve i), $576 \mathrm{mg} \mathrm{L}^{-1}$ (curve j) and $768 \mathrm{mg} \mathrm{L}^{-1}$ (curve k), it is found that the oxidation response current increases linearly, suggesting a good linear response.

Further studies by drawing a standard curve demonstrate the oxidation current signal $(\mathrm{i}, \mathrm{A})$ is proportional to the concentration of $\mathrm{COD}\left(\mathrm{C}, \mathrm{mg} \mathrm{L}^{-1}\right.$ of $\left.\mathrm{O}_{2}\right)$ for glucose solution over the range from 1.92 to $768 \mathrm{mg} \mathrm{L}^{-1}$, as shown in Fig. 4B. The linear regression equation is $\mathrm{i}=0.888 \mathrm{COD}$ and the correlation coefficient is 0.999 . Otherwise, the limit of detection (LOD)
Fig. 4 A: The amperometric response of $1.92 \mathrm{mg} \mathrm{L}^{-1}$ glucose with successive detections. B: The amperometric response of $1.92 \mathrm{mg} \mathrm{L}^{-1}$ glucose to eleven multiple micro-nano $\mathrm{Cu}-\mathrm{Cos}$. Other conditions are as in Fig. 2 a

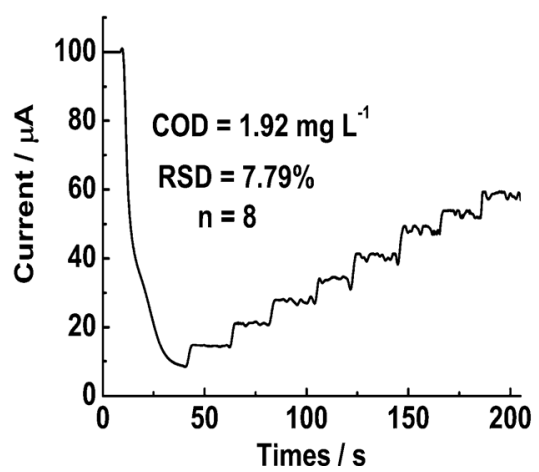

b

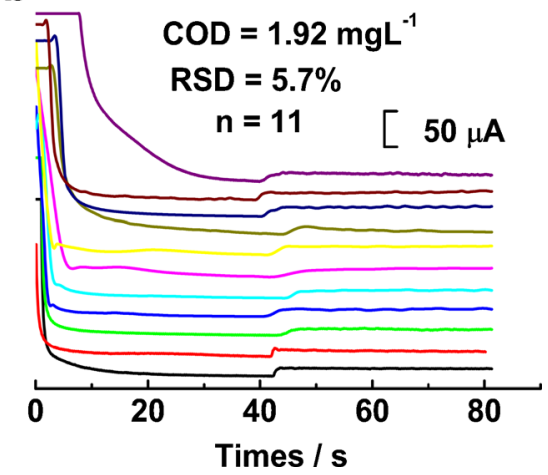


was evaluated to be $0.609 \mathrm{mg} \mathrm{L}^{-1}$ according to IUPAC regulations $(\mathrm{S} / \mathrm{N}=3)$.

Reproducibility, repeatability and influence of chloride ion

The reproducibility of one micro-nano $\mathrm{Cu}-\mathrm{Co} /$ gold electrode for successive detections was evaluated as Fig. 4A shown by adding glucose solutions of $1.92 \mathrm{mg} \mathrm{L}^{-1}$ glucose 8 times in succession, and a relative standard deviation (RSD) of $7.79 \%$ was obtained, suggesting very good reproducibility. Then, the reproducibility between multiple micro-nano $\mathrm{Cu}-\mathrm{Co} /$ gold electrodes was tested also using the response signal by glucose solutions of $1.92 \mathrm{mg} \mathrm{L}^{-1} \mathrm{COD}$. The value of RSD is just $5.7 \%$ for $11 \mu$-nano $\mathrm{Cu}$-Co films as Fig. 4B shows, indicative of excellent fabrication reproducibility and detection precision.

The influence of chloride ion on the amperometric detection of COD was also studied. In the presence of $0.02 \mathrm{M}$ chloride ion, the response current signal of glucose solution $\left(\mathrm{COD}=1.92 \mathrm{mg} \mathrm{L}^{-1}\right) \mathrm{kept}$ unchanged, revealing high tolerance level to chloride ion.

\section{Analytical application}

In order to testify the performance of this sensor in the analysis of real water samples, it was used to detect COD values of surface water samples that were collected from different lakes in Wuhan. Fig. 5 demonstrates the amperometric response of six water samples on the micro-nano $\mathrm{Cu}-\mathrm{Co} /$ gold surface. The COD concentration of water samples was detected using dichromate method, and the values are 26.26, 42.06, 52.23, $58.37,76.8$, and $92.65 \mathrm{mg} \mathrm{L}^{-1}$. It is found that the current response of water sample increases linearly with the COD value, suggesting promising application. Subsequently, the micro-nano $\mathrm{Cu}-\mathrm{Co} /$ gold was then used in a large number of

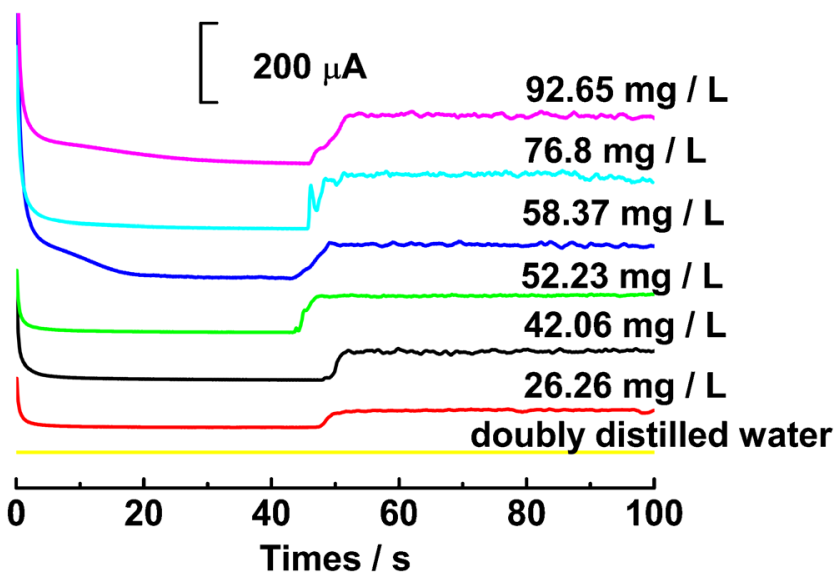

Fig. 5 Amperometric response of lake water samples on micro-nano $\mathrm{Cu}$ $\mathrm{Co} /$ gold electrode that was prepared at $-200 \mu \mathrm{A}$ for $100 \mathrm{~s}$

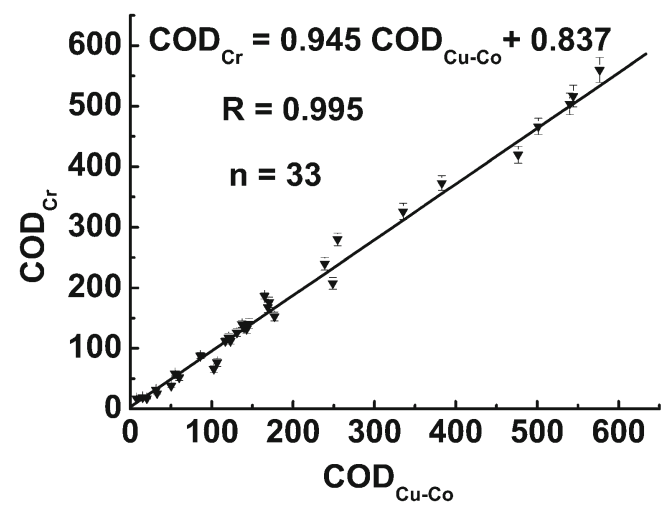

Fig. 6 Relationship between COD values of surface water obtained by micro-nano $\mathrm{Cu}-\mathrm{Co}$ electrochemical sensor and the conventional dichromate method

water samples. For testing the accuracy of micro-nano $\mathrm{Cu}-\mathrm{Co}$, the COD value of water samples were also analyzed by the conventional dichromate method. Each sample solution underwent three-parallel detections. Fig. 6 shows the relationship between the results obtained by this new method and by the conventional method for 33 surface water samples. It is found that the COD value detected by the dichromate titration method (indicated as $\mathrm{COD}_{\mathrm{Cr}}$ ) has good correlation with that by micro-nano $\mathrm{Cu}-\mathrm{Co}$ sensor (denoted as $\mathrm{COD}_{\mathrm{Cu}-\mathrm{Co}}$ ). The linear regression equation is $\mathrm{COD}_{\mathrm{Cr}}=0.945 \mathrm{COD}_{\mathrm{Cu}-\mathrm{Co}}+$ 0.837 , and the correlation coefficient is 0.995 , which indicated that the two methods have good accordance. Therefore, this new electrochemical method using micro-nano $\mathrm{Cu}-\mathrm{Co}$ is feasible for the detection of COD.

\section{Conclusion}

We report an alloy composite of micro-nano $\mathrm{Cu}-\mathrm{Co}$ which was facilely fabricated by one-step electrodeposition on gold electrode and then used as sensing materials for the electrochemical detection of COD employing glucose as standard substance. Due to the synergistic effects to oxygen-oxygen band breaking between copper and cobalt, together with high surface roughness and numerous micro and nano particles of the alloy composite, the fabricated electrode displays larger oxidative current response compared to gold electrode modified with copper or cobalt only. This sensing material not only shows the improved sensitivity and long-term stability, but also offers the advantages of simple fabrication process and efficient application in determination of COD in real water samples, which are essential for the COD detection in environmental monitoring. In a word, the present work demonstrates a promising application of intermetallic micro-nano material composite as highly active sensing materials in high-performance electrochemical sensors. Besides, this study also provides a general protocol to fabricate various sensors 
with intermetallic materials as sensing film for the sensitive detection of glucose and COD and provides a strategy for exploring the properties of intermetallic materials based on the property and interaction of monometallic component.

Acknowledgements This research is supported by the National Basic Research Program of China (973 Program, No. 2009CB320300), the National Natural Science Foundation of China (No. 81273024), and the National Environmental Protection Public Welfare Industry Targeted Research Fund of China (No. 201109058).

Open Access This article is distributed under the terms of the Creative Commons Attribution License which permits any use, distribution, and reproduction in any medium, provided the original author(s) and the source are credited.

\section{References}

1. Kim Y-C, Sasaki S, Yano K, Ikebukuro K, Hashimoto K, Karube I (2001) Photocatalytic sensor for the determination of chemical oxygen demand using flow injection analysis. Anal Chim Acta 432(1): $59-66$

2. Zhang Z, Yuan Y, Fang Y, Liang L, Ding H, Jin L (2007) Preparation of photocatalytic nano- $\mathrm{ZnO} / \mathrm{TiO}_{2}$ film and application for determination of chemical oxygen demand. Talanta 73(3):523-528

3. Yang J, Chen J, Zhou Y, Wu K (2011) A nano-copper electrochemical sensor for sensitive detection of chemical oxygen demand. Sensors Actuators B: Chem 153(1):78-82

4. Cheng Q, Wu C, Chen J, Zhou Y, Wu K (2011) Electrochemical Tuning the Activity of Nickel Nanoparticle and Application in Sensitive Detection of Chemical Oxygen Demand. The Journal of Physical Chemistry C 115(46):22845-22850

5. Liu W, Zhang Z, Zhang Y (2008) Chemiluminescence micro-flow system for rapid determination of chemical oxygen demand in water. Microchimica Acta 160(1-2):141-146

6. Akhoundzadeh J, Costas M, Lavilla I, Chamsaz M, Bendicho C (2013) Miniaturized and green method for determination of chemical oxygen demand using UV-induced oxidation with hydrogen peroxide and single drop microextraction. Microchimica Acta 180(11-12):1029-1036

7. Wang C, Wu J, Wang P, Ao Y, Hou J, Qian J (2013) Investigation on the application of titania nanorod arrays to the determination of chemical oxygen demand. Anal Chim Acta 767:141-147

8. Yuan S, Mao R, Li Y, Zhang Q, Wang H (2012) Layer-by-layer assembling $\mathrm{TiO}_{2}$ film from anatase $\mathrm{TiO}_{2}$ sols as the photoelectrochemical sensor for the determination of chemical oxygen demand. Electrochim Acta 60:347-353

9. Li J, Li L, Zheng L, Xian Y, Jin L (2006) $\mathrm{Rh}_{2} \mathrm{O}_{3} / \mathrm{Ti}$ electrode preparation using laser anneal and its application to the determination of chemical oxygen demand. Meas Sci Technol 17(7):1995

10. Ma C, Tan F, Zhao H, Chen S, Quan X (2011) Sensitive amperometric determination of chemical oxygen demand using $\mathrm{Ti} / \mathrm{Sb}-\mathrm{SnO}_{2} /$ $\mathrm{PbO}_{2}$ composite electrode. Sensors Actuators B: Chem 155(1):114 119

11. Orozco J, Fernández-Sánchez C, Mendoza E, Baeza M, Céspedes F, Jiménez-Jorquera C (2008) Composite planar electrode for sensing electrochemical oxygen demand. Anal Chim Acta 607(2):176-182

12. Wang J, Li K, Zhang H, Wang Q, Wang Y, Yang C, Guo Q, Jia J (2012) Condition optimization of amperometric determination of chemical oxygen demand using boron-doped diamond sensor. Res Chem Intermed 38(9):2285-2294

13. Bogdanowicz R, Czupryniak J, Gnyba M, Ryl J, Ossowski T, Sobaszek M, Darowicki K (2012) Determination of Chemical Oxygen Demand (COD) at Boron-doped Diamond (BDD) Sensor by Means of Amperometric Technique. Procedia Engineering 47:1117-1120

14. Yu H, Wang H, Quan X, Chen S, Zhang Y (2007) Amperometric determination of chemical oxygen demand using boron-doped diamond (BDD) sensor. Electrochem Commun 9(9):2280-2285

15. Li J, Li L, Zheng L, Xian Y, Ai S, Jin L (2005) Amperometric determination of chemical oxygen demand with flow injection analysis using $\mathrm{F}-\mathrm{PbO}_{2}$ modified electrode. Anal Chim Acta 548(1):199204

16. Ai S, Gao M, Yang Y, Li J, Jin L (2004) Electrocatalytic sensor for the determination of chemical oxygen demand using a lead dioxide modified electrode. Electroanalysis 16(5):404-409

17. Silva CR, Conceição CD, Bonifácio VG, Fatibello Filho O, Teixeira MF (2009) Determination of the chemical oxygen demand (COD) using a copper electrode: a clean alternative method. J Solid State Electrochem 13(5):665-669

18. Jirka AM, Carter MJ (1975) Micro semiautomated analysis of surface and waste waters for chemical oxygen demand. Anal Chem 47(8): 1397-1402

19. Kang YW, Cho M-J, Hwang K-Y (1999) Correction of hydrogen peroxide interference on standard chemical oxygen demand test. Water Res 33(5):1247-1251

20. Zheng Q, Zhou B, Bai J, Li L, Jin Z, Zhang J, Li J, Liu Y, Cai W, Zhu $X$ (2008) Self-Organized TiO2 Nanotube Array Sensor for the Determination of Chemical Oxygen Demand. Adv Mater 20(5): 1044-1049

21. Su Y, Li X, Chen H, Lv Y, Hou X (2007) Rapid, sensitive and on-line measurement of chemical oxygen demand by novel optical method based on UV photolysis and chemiluminescence. Microchem J 87(1):56-61

22. Yan J-M, Zhang X-B, Han S, Shioyama H, Xu Q (2009) Magnetically recyclable $\mathrm{Fe}-\mathrm{Ni}$ alloy catalyzed dehydrogenation of ammonia borane in aqueous solution under ambient atmosphere. $\mathrm{J}$ Power Sources 194(1):478-481

23. Fernandez JL, Walsh DA, Bard AJ (2005) Thermodynamic guidelines for the design of bimetallic catalysts for oxygen electroreduction and rapid screening by scanning electrochemical microscopy. M-Co (M: Pd, Ag, Au). J Am Chem Soc 127(1):357-365

24. Tang W, Zhang L, Henkelman G (2011) Catalytic activity of $\mathrm{Pd} / \mathrm{Cu}$ random alloy nanoparticles for oxygen reduction. The Journal of Physical Chemistry Letters 2(11):1328-1331

25. Silva F, Garcia J, Cruz V, Luna A, Lago D, Senna L (2008) Response surface analysis to evaluate the influence of deposition parameters on the electrodeposition of $\mathrm{Cu}-\mathrm{Co}$ alloys in citrate medium. J Appl Electrochem 38(12):1763-1769

26. Wang J, Wu C, Wu K, Cheng Q, Zhou Y (2012) Electrochemical sensing chemical oxygen demand based on the catalytic activity of cobalt oxide film. Anal Chim Acta 736:55-61

27. Yu H, Quan X, Chen S, Zhao H (2009) Flow injection analysis of chemical oxygen demand (COD) by using a boron-doped diamond (BDD) electrode. Environ Sci Technol 43(6):1935-1939

28. Qu X, Tian M, Chen S, Liao B, Chen A (2011) Determination of Chemical Oxygen Demand Based on Novel Photoelectro-bifunctional Electrodes. Electroanalysis 23(5):1267-1275

29. WU C, WU K-B (2013) Preparation of Electrochemical Sensor Based on Morphology-Controlled Platinum Nanoparticles for Determination of Chemical Oxygen Demand. Chinese Journal of Analytical Chemistry 41(5):704-708

30. Wang C, Wu J, Wang P, Ao Y, Hou J, Qian J (2013) Photoelectrocatalytic determination of chemical oxygen demand under visible light using $\mathrm{Cu}_{2} \mathrm{O}$-loaded $\mathrm{TiO}_{2}$ nanotube arrays electrode. Sensors Actuators B: Chem 181:1-8 
31. Chen S, Yuan R, Chai Y, Hu F (2013) Electrochemical sensing of hydrogen peroxide using metal nanoparticles: a review. Microchimica Acta 180(1-2):15-32

32. Wang F, Liao Y, Ren Y, Chen Z (2010) A novel method for Darabinitol determination based on a nano-structured sensing film by one-step electrodeposition. Microchimica Acta 170(1-2):9-15
33. Shi H, Zhang Z, Wang Y, Zhu Q, Song W (2011) Bimetallic nano-structured glucose sensing electrode composed of copper atoms deposited on gold nanoparticles. Microchimica Acta 173(1-2):85-94

34. Dobbs RA, Williams RT (1963) Elimination of Chloride Interference in the Chemical Oxygen Demand Test. Anal Chem 35(8):1064-1067 